\title{
QUALIDADE DE VIDA VERSUS CONDIÇÕES DE VIDA: UM BINÔMIO DISSOCIADO
}

\author{
QUALITY OF LIFE VERSUS LIVING CONDITIONS: A DISASSOCIATED BINOMIAL
}

Rosemeire Aparecida Scopinho ${ }^{1}$

Resumo Neste artigo, defendo que as políticas de promoção da qualidade de vida no trabalho atualmente adotadas pelas empresas podem servir como um paliativo para aliviar os sintomas provocados pela intensificação do trabalho, mas não logram resolver as causas estruturais dos problemas enfrentados pelos trabalhadores. Reforço esta idéia argumentando que a necessidade de 'humanizar' o trabalho tem tradição na preocupação gerencial e, reafirmando a polissemia, a não materialidade e a relatividade do conceito de 'qualidade de vida no trabalho', demonstro que ele é um modismo gerencial que assume sentidos distintos nas representações de gestores e de trabalhadores e que, atualmente, o trabalho não oferece condições para que os trabalhadores realizem o processo de adaptação biopsicossocial necessário para garantir a vida. Defendo a adoção da noção de 'condições de vida' porque ela remete ao controle dos trabalhadores sobre as relações e condições de trabalho como uma possibilidade, o que requer entender o processo de produção de conhecimento sobre o trabalho como representações socialmente construídas e partilhadas.

Palavras-chave trabalho e condições de vida; gestão do trabalho; qualidade de vida no trabalho.
Abstract In this paper, I argue that policies to promote quality of life at work currently adopted by enterprises can serve as a stopgap measure to relieve symptoms caused by the intensification of work, but failed to address the structural causes of the problems faced by workers. I reinforce this idea by arguing that the need to "humanize" work has a tradition of managerial concern. I demonstrate by reaffirming polysemy, the non-materiality and the relativity of the concept of 'quality of work life', that the latter is a management fad that has different meanings in managers and workers representations and that work currently does not provide conditions for workers to carry out the process of biopsychosocial adaptation necessary to guarantee life. I support the adoption of the concept of 'living conditions' because it refers to workers' control over working relations and working conditions as a possibility, which requires the understanding of the process of work knowledge production as socially constructed and shared representations.

Keywords work and living conditions, work management, quality of work life. 


\section{Uma perspectiva crítica quanto ao viver e suas transformações possíveis}

O artigo de Valquíria Padilha, "Qualidade de vida no trabalho num cenário de precarização: a panacéia delirante", trata de uma questão central, tanto para os trabalhadores quanto para os gestores, ou seja, a relação entre introdução de novas formas de organização do trabalho e as estratégias empresariais para obter a adesão dos trabalhadores aos objetivos de produção estabelecidos. A autora defende que as políticas de promoção da qualidade de vida no trabalho atualmente adotadas pelas empresas podem servir como um paliativo para aliviar os sintomas provocados pela intensificação do trabalho, mas não logram resolver as causas estruturais dos problemas enfrentados pelos trabalhadores.

O meu comentário sobre o artigo reforça esta tese ao tomar quatro questões que, a meu ver, podem contribuir com esta discussão.

Primeiramente, é importante lembrar que a necessidade de 'humanizar' o trabalho tem tradição na preocupação gerencial. Especialmente desde que Elton Mayo investigou os fatores relacionados à produtividade na Western Eletric Company, introduzindo no ideário gerencial palavras e conceitos tais como ênfase nas pessoas, motivação, liderança, dinâmica de grupo, comunicação, entre outros, até os dias de hoje, quando entram em cena as novas tecnologias de gestão, tais como os Regimes de Trabalho de Alto Desempenho e os Kanbans Emocionais, o fato é que as políticas de gestão dos trabalhadores, entendidas aqui como mediadoras de relações sociais complementares e antagônicas (Fleury, 1994), esforçam-se para resgatar o que o trabalhador pode perder quando o sentido do seu trabalho é incorporado nas engrenagens e/ou nos circuitos eletrônicos componentes das máquinas do nosso tempo.

Seja qual for o nome que se dê para o que se perde - motivação (Maslow, 1973; MacGregor, 1979), satisfação (Siever, 1990; Coda, 1990), desejo (Dejours et al., 1994) - acontece o que já tem sido amplamente demonstrado: o envolvimento do sujeito com o trabalho diminui e este é um problema central para os que organizam e administram a produção porque isto pode contribuir, decisivamente, para diminuir a produtividade e a qualidade dos produtos e aumentar os custos de produção. Iniciada nos tempos de Mayo, intensifica-se, cada vez mais, a corrida gerencial em busca de uma fórmula organizativa que procure abarcar a dimensão do conhecimento e dos sentimentos dos trabalhadores que possam estar envolvidos na realização do trabalho para que, estando essas dimensões também sob o controle do gestor, o trabalho aconteça tal como foi prescrito para atingir as metas de produtividade, qualidade e redução de custos impostas pelo mercado.

Os estudos de caso que eu realizei nos setores sucroalcooleiro e de energia elétrica sobre as consequências da introdução das 'novas'2 estratégias de gestão para os trabalhadores atestam essas afirmações. Ambos os setores foram estudados no momento em que deixaram de ser regulados diretamente pelo 
Estado e passaram a funcionar de acordo com as regras da economia de mercado. No setor sucroalcooleiro, a desregulamentação ocorreu nos anos 1990, com a extinção do Instituto do Açúcar e do Álcool (IAA) (Scopinho, 2000; 2003), e o setor de energia elétrica, nos anos de 2000, foi privatizado (Scopinho, 2002; 2009). A partir da análise desses casos foi possível constatar que, no contexto da reestruturação das empresas, pioraram os agravos à saúde e a qualificação dos trabalhadores. Renovaram-se os discursos gerenciais e as políticas de gestão, mas no sentido de realizar o marketing social das empresas e de construir imagens de responsabilidade e de utilidade social. A principal preocupação estava voltada para a qualidade dos produtos e serviços, mas o mesmo não se verificava em relação à qualidade de vida dos trabalhadores, cujos índices de desemprego, acidentários ou de adoecimento e os depoimentos sobre a ausência de condições para obter a qualificação necessária para continuar trabalhando denunciavam a falácia dos discursos.

Resulta da constatação da mencionada histórica corrida gerencial em busca dos sentidos e conteúdos que o trabalho humano vem perdendo ao ser objeto do crescente e acelerado processo de inovações tecno-organizacionais a segunda questão a comentar: a polissemia, a não materialidade e a relatividade do conceito de qualidade de vida, atributos já apontados por Minayo, Hartz e Buss (2000). A idéia de qualidade de vida perde-se ainda mais nos meandros dos modismos gerenciais do nosso tempo e se transforma em qualidade de vida no trabalho (QVT), conceito este que, por sua vez, segundo Lacaz (2000), tem sido largamente difundido hoje, mas cuja trajetória inclui vários enfoques, desde o da preocupação gerencial com a produtividade e a qualidade do processo produtivo até o da preocupação com as condições e o ambiente de trabalho incorporando demandas e requisitando a participação dos trabalhadores.

Quanto a esta questão, penso que, primeiro, temos uma qualidade de vida e uma qualidade de vida no trabalho, como se trabalho fosse da vida coisa separada; segundo, temos receitas universais como se todas as empresas e todos os trabalhadores fizessem parte de um universo único, homogêneo e estático; terceiro, cada qual inventa e vende a sua receita como se ela fosse a primeira, a única e a melhor.

Assim, qualidade de vida e qualidade de vida no trabalho tornaram-se jargões vazios e receitas são veiculadas e vendidas criando um mercado específico: o mercado dos modismos gerenciais (Fiamengui, 2002) onde, via de regra, se criam novos nomes para os mesmos problemas e receitas. E, por mais que se esforcem os gestores bem-intencionados, parece que nada - livros e revistas especializadas e de autoajuda, cursos, treinamentos e congressos - pode ser suficiente e capaz de interromper a incessante busca por fórmulas mágicas que resolvam os problemas relacionados ao não envolvimento dos trabalhadores com o trabalho; e também por mais que os trabalhadores trabalhem, o esforço nunca é suficiente para garantir condições de estabilidade no emprego, o que, 
de fato, poderia ser um elemento importante na preservação da qualidade de vida, dentro e fora do trabalho. A questão é que as regras do jogo estão fora do controle dos sujeitos, estão no mercado, abstração que toma forma concreta no imaginário gerencial e social que lhe atribui características tipicamente humanas: nervoso, calmo, exigente, entre outras, tornando-o entidade que controla o curso da vida das pessoas.

A terceira questão diz respeito às diferenças de concepções e representações existentes entre gestores e trabalhadores, quando se trata de entender o que é qualidade de vida, saúde-doença, liberdade, entre outros conceitos. $\mathrm{O}$ exame dessas diferenças coloca em xeque a existência de denominadores comuns que se pretende alcançar com as políticas de QVT. A força da mão invisível impõe ao capital a necessidade de rever estratégias para sobreviver; este requer liberdade para organizar e realizar a produção de acordo com os imperativos impostos pela dinâmica do mercado. Se, como diz Vasapollo (2006), flexibilizar é dar a liberdade que o capital necessita para empregar/desempregar, reduzir, ampliar ou rearranjar as jornadas de trabalho, modificar o regime de contratação e os salários, terceirizar ou quarteirizar atividades meios, entre outras estratégias para reduzir custos de produção, como forma de manter a 'saúde' da empresa, por sua vez, a saúde dos trabalhadores, como diz Dejours, também depende da liberdade:

(...) a saúde, para cada homem, mulher ou criança é ter meios de traçar um caminho pessoal e original, em direção ao bem-estar físico, psíquico e social. (...) para o bemestar físico é preciso ter liberdade para regular as variações que aparecem no estado do organismo (...) A saúde é a liberdade de dar a esse corpo a possibilidade de repousar, é a liberdade de lhe dar de comer quando ele tem fome, de fazê-lo dormir quando ele tem sono, de fornecer-lhe açúcar quando baixa a glicemia. É, portanto, a liberdade de adaptação (Dejours, 1986, p. 11).

A qualidade de vida no trabalho, cuja expressão maior poderia ser aquilatada pelo estado geral de saúde dos trabalhadores, não depende apenas da oferta de serviços assistenciais públicos ou empresariais e nem tampouco de políticas e programas de gestão que ofereçam ginástica laboral, massagens, salas de descanso e outros recursos de relaxamento antes e/ou depois da jornada de trabalho. Depende, essencialmente, de um pacto que se faça no planejamento do trabalho e que se cumpra ao realizá-lo, que também leve em conta as necessidades de adaptação dos trabalhadores. No artigo, Valquíria Padilha toca na questão central ao mencionar que política de QVT “(...) se configura em 'meio' quando deveria ser 'fim"' (Padilha, 2009, p. 555).

As contribuições de Vasapollo e Dejours bastam para nos levar à quarta questão a ser comentada: como ter qualidade de vida no trabalho se, ao trabalhar, não se tem as condições para realizar o processo de adaptação biopsicossocial 
necessário para garantir a vida? A liberdade que se oferece ao capital retira a que o trabalhador deveria ter para realizar o processo de adaptação. É neste sentido que QVT é um jargão vazio, como diz Padilha “(...) 'meio' para maquiar problemas de ordem estrutural (...)" (Padilha, 2009, p. 555).

Por isto, eu opto pelo uso da noção de condições de vida em vez de qualidade de vida ou qualidade de vida no trabalho porque me parece que a primeira traz uma referência mais clara à questão do controle, como uma possibilidade para o sujeito. Vazia, porque não leva em conta a assimetria de poderes existente no mundo da produção, a idéia de QVT parece desconsiderar as lutas históricas dos trabalhadores pelo controle do trabalho por meio da conquista de direitos trabalhistas e sociais e coloca nas 'novas' estratégias de gestão todos os esforços para melhorar as condições de trabalho. Negam-se os direitos historicamente adquiridos, naturaliza-se a precarização do trabalho como fato inexorável e inerente a uma sociedade que se 'moderniza' e, como diz Dejours (2000), banalizam-se as injustiças sociais cometidas nos ambientes de trabalho e, ao mesmo tempo, produzem-se as receitas de QVT. A precariedade do trabalho não diz respeito apenas à falta de vínculos formais, mas também ao descumprimento generalizado das normas e direitos sociais que definem como o trabalho deve se realizar dentro dos padrões socialmente aceitáveis de saúde e segurança para os que trabalham. Naturalizar a precariedade, de um lado, e criar receitas de bem viver para disfarçar a insalubridade, a periculosidade e a penosidade do trabalho, do outro, não é uma forma mais sutil de ter o controle sobre os trabalhadores?

Um dos importantes elementos presentes nas atuais políticas de gestão são, justamente, as formas de controle que tendem a ser mais simbólicas do que coercitivas e punitivas. Assim, cresce a importância de desenvolver estudos sobre a relação trabalho-subjetividade porque tais políticas funcionam como um molde, forma dentro do qual se constrói a subjetividade, a história e a identidade coletiva e singular do sujeito, e se fixam as regras de convivência social. $\mathrm{O}$ "sujeito trabalhador" define-se (...) “a partir das vivências e experiências adquiridas no mundo do trabalho" (...) e está (...) "atado às normas sociais e construído nas tramas que definem tais normas" (...) (Nardi, Tittoni, Bernardes, 1999, p. 240).

Não me parece possível distinguir, analiticamente, condições de trabalho e condições de vida, porque ambas formam entre si um conjunto, configurado pela parcela do valor produzido que cabe aos trabalhadores, na forma de salário ou renda e nos bens coletivos disponíveis na sociedade, e pelas condições do próprio processo de trabalho.

Condições de trabalho são as circunstâncias do ambiente - de natureza física, química, biológica, mecânica, ergonômica, psíquica - que desafiam e mobilizam as capacidades biopsicossociais e culturais dos trabalhadores para atingir os objetivos da produção. Da interação dos trabalhadores com estas condições, 
tanto pode resultar em desgaste ou adoecimento quanto em desenvolvimento de potencialidades psicofísicas, a depender da lógica de organização do trabalho e do grau de controle que eles possam exerce sobre ele (Laurell e Noriega, 1989; Dejours et al., 1994). Assim, a qualidade de vida no trabalho não diz respeito apenas à ausência de adoecimento ou possibilidade de ter qualificação. Trabalho não é apenas um espaço de realização da mais-valia e de dominação do capital, mas também é espaço de produção de criação e difusão de valores coletivistas, de resistências e de lutas históricas dos trabalhadores pelo controle das relações e condições de trabalho, na tentativa de saneá-las. O trabalho pode ser espaço de construção da saúde ou de formação humana quando o modo de organização possibilita um campo de desafios e de liberdades para responder a demandas complexas e imprevistas, expressar emoções, desenvolver habilidades e reafirmar a autoestima. Como dizem Dejours et al. (1994), nas situações de trabalho, conscientemente ou não, se constrói a saúde através da mobilização das potencialidades de adaptação próprias do ser humano, que tanto permitem enfrentar os desafios e gerar prazer quanto o evitar o sofrimento.

A noção de condições de vida refere-se à reprodução social, no seu sentido objetivo como possibilidade de acesso, por meio do trabalho, aos bens de consumo coletivo - moradia, infraestruturas sociais e de saneamento, educação, saúde, transporte, lazer etc. - e subjetivo, referente à possibilidade de ter controle sobre as relações sociais e políticas no trabalho, ao poder de decisão e de autogestão. No entanto, a relação entre condições materiais e subjetivas de vida (incluindo a cultura e as experiências vividas) não é unívoca e evidente. É necessário recorrer à noção de modo de vida para entender como as condições objetivas são vivenciadas pelos trabalhadores, que podem ter maior eficácia explicativa ao se remeter aos valores, tradições e códigos morais presentes nos seus universos simbólicos (Telles, 1992; Lobo, 1992). Podem-se destacar várias dimensões da vida humana como recorte e forma de operacionalizar o conceito, entre elas, a saúde, a qualificação e formação profissional, a relação trabalho e meio ambiente, a formação política dos sujeitos para se organizarem nos locais de trabalho.

Breilh (2003) e Istúriz (2003) apontam que no atual cenário políticoeconômico, fortemente marcado pela iniquidade e pelas inúmeras formas instituídas de deterioração dos direitos humanos, surgem padrões de morbidade, relacionados à impossibilidade concreta dos trabalhadores atenderem suas demandas e funções psicofisiológicas básicas. Tem sido amplamente debatido que a saúde não é uma questão essencialmente biológica, individual e curativa e o nosso corpo, de certo modo, expressa o que acontece na ordem social. Breilh (2003) entende que o perfil epidemiológico de um grupo é expresso pelo movimento contraditório entre os processos que protegem e os que destroem o seu estilo de vida característico que, por sua vez, limitam os modos de vida dos seus membros. Para o autor: "La vida y la salud de las (os) trabajadores (as) 
dependen de esse movimiento entre los procesos que nos protegen y los que nos deterioran, y el desarollo de todos ellos depende de la capacidad de disfrute de los derechos humanos" (Breilh, 2003, p. 940).

Decorre desta opção teórica uma questão metodológica que não pode ser desconsiderada, quando se trata de pensar as implicações das estratégias gerenciais na vida dos trabalhadores, e que passa por adotar uma perspectiva que trata o processo de produção do conhecimento como construção social possibilitada pelo diálogo travado entre sujeitos portadores de saberes distintos. Os trabalhadores constroem e partilham sentidos sobre a realidade vivida com a finalidade não apenas de interpretá-la, mas também de transformá-la, sentidos esses que expressam suas identidades sociais e culturais e não são abstrações puras, porque tanto são gerados quanto se integram às suas experiências e práticas cotidianas, refletindo e constituindo reflexos da estrutura social, da ideologia e da cultura que as sustentam. Ou seja, pensar em análise das políticas de QVT traz como consequência conhecer as suas implicações concretas para os trabalhadores a partir de estudos de caso metodologicamente desenhados para compreender o cotidiano de vida e trabalho.

Esta opção metodológica é fundamental para a compreensão do objeto proposto, o que dificilmente pode ser feito a partir da escolha de procedimentos simplificados, tais como entrevistas padronizadas e pontuais. Para dialogar é preciso mergulhar no cotidiano, ${ }^{3}$ no convívio micropolítico, obviamente, sem deixar de reconhecer as diferenças existentes entre os mundos (do pesquisador e do pesquisado) que, ao mesmo tempo em que necessitam manter as suas identidades próprias e diferenças, criam espaços de articulação e de interface onde o conhecimento se constrói. E ainda sem perder de vista os condicionantes estruturais que permeiam as relações de trabalho e as diversas formas de luta social pela melhoria das condições de trabalho e de vida. Lembrando Bourdieu (1997), é feito um esforço para entender o sujeito desde onde ele se encontra na estrutura social.

Por último, vale dizer que a relação trabalho-condição de vida, seja pelo viés da saúde, da qualificação e formação profissional ou da participação política, vem sendo investigada, predominantemente, no mundo urbano e no âmbito do trabalho organizado sob o princípio da heterogestão. A recente proliferação das formas de trabalho cooperado e autogestionário na cidade e no campo, que acontece em meio às reformas econômicas e das políticas sociais e à reestruturação do mundo do trabalho, torna relevante a reflexão sobre questões tais como: essas experiências, realmente, situam-se no campo de uma 'outra economia' ou estão integradas na lógica econômica hegemônica? Como acontece a gestão do trabalho nesses espaços? As experiências contribuem para melhorar as condições de vida dos trabalhadores? Essas questões têm orientado, atualmente, as minhas pesquisas sobre o tema. 


\section{Notas}

1 Professora adjunta do Departamento de Psicologia da Universidade Federal de São Carlos, (UFSCar), São Paulo, Brasil. Doutora em Sociologia pela Universidade Estadual Paulista Júlio de Mesquita Filho (Unesp).<scopinho@ufscar.br>

Correspondência: Rodovia Washington Luiz, Km 235 (SP 310), Monjolinho, São Carlos, SP, Brasil, CEP 13565-905.

2 Digo 'novas' com a ressalva das aspas porque, apesar do discurso dos gestores, que, à primeira vista, parece inovador, os aprofundamentos dos estudos de caso realizados a partir do confronto entre os discursos de gerentes, técnicos, trabalhadores e sindicalistas, as observações realizadas nos locais de trabalho e as informações retiradas de documentos mostraram que as atuais estratégias, na prática, formam um combinado de princípios e técnicas do modelo tayloristas-fordistas, passando pelo humanismo da Escola de Relações Humanas até chegar às técnicas típicas do ohnismo.

3 Para Spink (1991, p. 27, grifos do autor), o cotidiano “(...) não é um vazio de restos aleatoriamente espalhados pelo chão. Ao contrário, é o lugar onde a gente se conhece como gente - comendo, amando, brigando, andando e trabalhando". Quer dizer, é no cotidiano micropolítico que a vida do grupo se manifesta mais intensamente em toda a sua riqueza de significados. No entanto, o cotidiano é mais do que um conjunto de ações diárias e corriqueiras, é também reflexo e antecipação da história, como lembrou Whitaker (2002, p. 45): “(...) é no cotidiano que se podem colher os dados da transformação cultural e realizar a observação das práticas culturais - sua desestruturação e reconstrução - e é em meio às práticas culturais e ao trabalho que se tecem as representações que organizam os homens no processo dinâmico em que constroem a História."

\section{Referências}

BOURDIEU, Pierre. Compreender. In: et al. (org). A miséria do mundo. 4. ed. Petrópolis: Vozes, p. 693-713, 1997.

BREILH, Jaime. De la vigilancia convencional al monitoreo participativo. Ciência \& Saúde Coletiva, v. 8, n. 4, p. 937-951, 2003.

CODA, Roberto. Relação entre motivação, satisfação no trabalho e administração de RH. In: BERGAMINI, Cecília W.; CODA, Roberto. Psicodinâmica da vida organizacional: motivação e liderança. São Paulo: Pioneira, 1990.

DEJOURS, Christofhe. Por um novo conceito de saúde. Revista Brasileira de Saúde Ocupacional, v. 14, n. 54, p. 07-11, abr./mai./jun., 1986. et al. Psicodinâmica do trabalho: contribuições da escola dejouriana à análise da relação prazer, sofrimento e trabalho. São Paulo: Atlas, 1994. 145 p.

A banalização da injustiça social. 3 ed. Rio de Janeiro: FGV Editora, 2000.

FLEURY, Maria T. L. Relações de trabalho e políticas de gestão: uma história de questões atuais. Revista de Administração, São Paulo, v. 27, n. 4, p. 5-15, out./dez., 1992.

FIAMENGUI NETO, Aquiles. Modismos gerenciais e cultura organizacional: um estudo de caso sobre a adoção de sistemas ERP. Dissertação (Mestrado em Desenvolvimento Regional) 
- Uniara-Centro Universitário de Araraquara, Araraquara, SP, 2004. 166 p.

ISTÚRIZ, Oscar F. Reflexiones sobre la globalización y su impacto sobre la salud de los trabajadores y el ambiente. Ciência \& Saúde Coletiva, v. 8, n. 4, p. 887-896, 2003.

LACAZ, Francisco. A. de C. Qualidade de vida no trabalho e saúde/doença. Ciência \& Saúde Coletiva, v. 5, n.1, p. 151-161, 2000.

LAURELL, Asa C.; NORIEGA, Mariano. Processo de produção e saúde: trabalho e desgaste operário. São Paulo: Hucitec, 1989.

LOBO, Elisabeth S. Caminhos da Sociologia no Brasil: modos de vida e experiência. Tempo Social - Revista de Sociologia da USP, v. 4, n. 1-2, p. 7-15, 1992.

MAcGREGOR, Douglas. O lado humano da empresa. In: BALCÃO, Yolanda F.; CORDEIRO, Laerte L. O comportamento humano na empresa: uma antologia. 2. ed.. Rio de Janeiro: FGV Editora, 1973.

MASLOW, Abraham F. Uma teoria da motivação humana. In: BALCÃO, Yolanda F.; CORDEIRO, Laerte L. O comportamento humano na empresa: uma antologia. 2. ed. Rio de Janeiro, FGV Editora, 1973.

MINAYO, Maria C. de S.; HARTZ, Zulmira M. de A.; BUSS, Paulo M. Qualidade de vida e saúde: um debate necessário. Ciência \& Saúde Coletiva, v. 5, n. 1, p. 7-18, 2000.

NARDI, Henrique C., TITTONI, Jaqueline; BERNARDES, Jefferson S. Subjetividade e trabalho. In: CATANI, Antônio D. Trabalho e tecnologia: dicionário crítico. 2. ed. Petrópolis, RJ, Vozes, 1997. 240-246 p.

SCOPINHO, Rosemeire A. Qualidade total, saúde e trabalho: uma análise em empresas sucroalcooleiras. Revista de Administração Contemporânea, v. 4, n. 1, p. 93-112, jan./abr., 2000.
Privatização, reestruturação e mudanças nas condições de trabalho: o caso do setor de energia elétrica. Cadernos de Psicologia Social do Trabalho, vol. 5, 19-36, 2002.

Vigiando a vigilância: saúde e segurança no trabalho em tempos de qualidade total. São Paulo: Editora Annablume: Fapesp, 2003. 284 p.

Entre o medo do trabalho e o medo de não trabalhar: eletricitários e privatização. In: NAVARRO, Vera L.; PADILHA, Valquíria (Orgs.) Retratos do trabalho no Brasil. Uberlândia, Edufu, 2009. p. 255-278.

SIEVER, Burkard. Além do sucedâneo da motivação. In: BERGAMINI, Cecília W.; CODA, Roberto. Psicodinâmica da vida organizacional: motivação e liderança. São Paulo: Pioneira, 1990.

SPINK, Peter. O resgate da parte. Revista de Administração, v. 26, n. 2, p. 22-31, 1991.

TELLES, Vera. da S. A experiência da insegurança: trabalho e família nas classes trabalhadoras urbanas em São Paulo. Tempo Social Revista de Sociologia da USP, v. 4, n. 1-2, p. 53-93, 1992.

PADILHA, Valquíria. Qualidade de Vida no Trabalho num contexto de precarização: a panaceia delirante. Trabalho, Educação e Saúde, Rio de Janeiro, p. 549-563], nov. 2009/fev. 2010.

VASAPOLLO, Luciano. O trabalho atípico e a precariedade: elemento estratégico determinante do capital no paradigma pós-fordista. In: ANTUNES, Ricardo (Org.). Riqueza e miséria do trabalho no Brasil, São Paulo: Boitempo, 2006.

WHITAKER, Dulce. C. Sociologia Rural: questões metodológicas emergentes. São Paulo, Presidente Wenceslau: Editora Letras a Margem, 2002. 